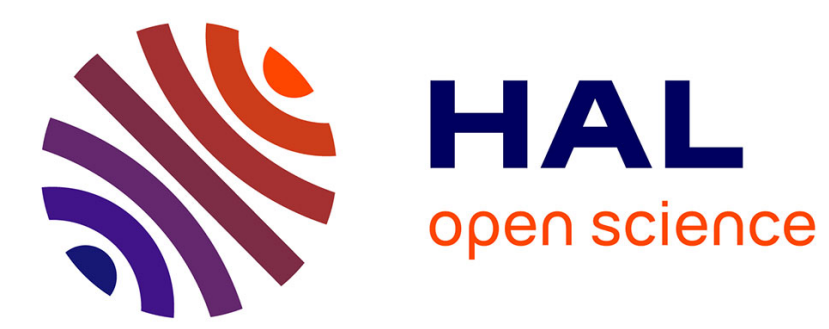

\title{
Biobanking in forestry practices: towards an agency policy?
}

Fabien Milanovic, Francois Lefèvre

\section{To cite this version:}

Fabien Milanovic, Francois Lefèvre. Biobanking in forestry practices: towards an agency policy?. New Genetics and Society, 2018, 37 (4), pp.411 - 434. 10.1080/14636778.2018.1548270 . hal-02621657

\section{HAL Id: hal-02621657 https://hal.inrae.fr/hal-02621657}

Submitted on 6 Jan 2022

HAL is a multi-disciplinary open access archive for the deposit and dissemination of scientific research documents, whether they are published or not. The documents may come from teaching and research institutions in France or abroad, or from public or private research centers.
L'archive ouverte pluridisciplinaire HAL, est destinée au dépôt et à la diffusion de documents scientifiques de niveau recherche, publiés ou non, émanant des établissements d'enseignement et de recherche français ou étrangers, des laboratoires publics ou privés. 


\section{Biobanking in forestry practices: towards an agency policy?}

\section{Fabien Milanovic \& François Lefèvre}

To cite this article: Fabien Milanovic \& François Lefèvre (2018) Biobanking in forestry practices: towards an agency policy?, New Genetics and Society, 37:4, 411-434, DOI: 10.1080/14636778.2018.1548270

To link to this article: https://doi.org/10.1080/14636778.2018.1548270

\section{Published online: 22 Nov 2018.}

Submit your article to this journal ¿

Џ Article views: 51

Q View related articles $\asymp$

View Crossmark data ¿

Citing articles: 1 View citing articles ๘ 


\title{
Biobanking in forestry practices: towards an agency policy?
}

\author{
Fabien Milanovic $^{\mathrm{a} *}$ and François Lefèvre ${ }^{\mathrm{b}}$ \\ ${ }^{a}$ Sup'Biotech, Villejuif, France; ${ }^{b}$ INRA, URFM Ecologie des Forêts Méditerranéennes, \\ UR629, Avignon, France
}

(Received 16 March 2018; final version received 8 November 2018)

The conservation-management of living beings is not only an issue in medicine. Based on a collaboration between a sociologist and a geneticist, this paper aims to document the banking practices in the sector of forest genetic resources, which raises specific questions. Drawing on a fieldwork investigation we further explore the various possibilities that biobanking in forestry conceal in terms of diversity of banked entities and banking practices. We argue that there is a consistent heterogeneity of entities and practices, which reflects the distribution of the agency conferred to the involved entities. This heterogeneity is related to the awareness of uncertainties, which change the relative importance of the different modes of agency in biobanking. Beyond seldom recognition of the diversity of modes of agency, we conclude by claiming for the need of a consistent agency policy.

Keywords: biobanking; forest genetic resources; agency; in situ; ex situ; conservation

Biobanks in medicine consist of collecting elements of the human body, conserving them, using them to transform, reproduce, using them for reproductive purposes or diagnose distribute them, etc. In this special issue, many cases illustrate these various uses and purposes. However, the question of the conservation-management of living beings is not only an issue in medicine: it is also an issue for other activities involving living organisms. In this paper, we focus on plants, more particularly forests whose conservation raises specific questions. Making ex situ collections for varietal innovation dates back to the 1920s with Nikolai Vavilov, who was a pioneer in understanding genetic diversity as a resource for agriculture. He considered it strategic to identify and bring together this diversity. From this we can date the first systematic collections of genetic resources of cultivated plants (Fenzi and Bonneuil 2016). Then, later, with the erosion of biodiversity, the idea

\footnotetext{
*Email: fabien.milanovic@supbiotech.fr
} 


\section{F. Milanovic and F. Lefèvre}

that emerged preserving in itself is desirable. How do these ideas drive forest conservation practices such as tree banking? Before the 1990s or so, the conservation of forest genetic resources ${ }^{1}$ in a supposedly stable environment was justified: that is, only the genetic diversity was evolvable. Since then, with the consideration of the acceleration and intensity of climate change, there has been a twofold dynamic: the evolutionary dynamics of resources has been complemented by the dynamics of environmental change. While we have scientific theories in evolutionary sciences that allow us to consider the evolutionary dynamics of forest genetic resources (Soulé and Wilcox 1980), we have much more difficulty understanding the dynamics of environmental change. So, the uncertainty is unbalanced between the two dynamics.

If until the 1990 s, plant collections were used for varietal innovation and "archiving" purposes, ${ }^{2}$ what are the possibilities that the organization of conservation conceals in terms of diversity of existing conservation practices (combination of ex situ and in situ)? What kind of relationship exists between forest genetic resources (FGR) and their environment (in terms of stakes, timescales, actors, institutions and states of the world that they carry)? To address these questions, we focus on forest genetic resources and related banking activities but before getting to the heart of the matter, we would like to clarify the context in which our questioning takes place. More than 40 years ago, introducing the concept of resilience in ecology, Holling wrote:

Flowing from this would be not the presumption of sufficient knowledge, but the recognition of our ignorance; not the assumption that future events are expected, but that they will be unexpected. The resilience framework can accommodate this shift of perspective, for it does not require a precise capacity to predict the future, but only a qualitative capacity to devise systems that can absorb and accommodate future events in whatever unexpected form they may take. (Holling 1973)

A new way in forestry emerges in this context of unpredictability (Von Detten 2011), which combines two objectives: short-term adaptation to a changing environment and long-term preservation of future options to cope with uncertain futures. Coping with a context of permanent change and multiple uncertainties has two main consequences: (i) the conservation of biological diversity as a suite of options for uncertain futures is a central issue for adaptive strategies, and (ii) priority is given to dynamic strategies of conservation that take advantage of the evolvable nature of the conserved entities (Lefèvre et al. 2014). By focusing particularly on biobanks and forest genetic resources, we wish to demonstrate that in a context of unpredictability, the diversity and evolvability of the forest entities in the biobanks are needed in order to preserve a diversity of options capable of enhancing the adaptability of the biotic entities concerned. More precisely, if forests are destined to exist differently as a result of climate change, are not the arrangements that we, humans, maintain with them also likely to evolve? Is this not a redistribution of capacities for action between forest and human 
entities, between humans and non-humans? To what extent do uncertainty issues redefine the modalities of distribution of the agency of forest living organisms in forest banking? ${ }^{3}$

We focus on the different ways in which "humans adjust to an environment that includes things, other humans and other living non-human beings" (Thévenot 1994, see also 2011), while maintaining a distance between the classical dichotomies between subject and object, active and passive, nature and culture (Conein, Dodier, and Thévenot 1993; Latour 1994). Hence the use of the notion of agency defined as a capacity for action (a power to act) that operates a shift from the intentional human subject to a multiplicity of agents. ${ }^{4}$ This notion is part of a theoretical perspective in which the power to act is not grasped in terms of stable characteristics inherent in the individual or the environment but in relation to a developing situation. It refers to an approach "which does not start from constituted individuals, nor from already given environments, but from the structural coupling between individual and environment, by which they do not cease to occur and transform." (Bidet, Boutet, and Chave 2013, 176). Beyond individuals (humans), the same applies to biotic entities to which more or less agency can be recognized and conferred depending on the situations in which they are involved. It's this differential in capacity for action that interests us. Our argument is that this distribution of agency (between humans and non-humans, between biotic entities and their environment), is part of an agency policy that we propose to bring into light.

In this article, we highlight the challenge of multiplying "nature-society" relationships that aim to achieve less control over beings: i.e. a redistribution of agency between humans and non-humans (Latour 2017). This is expressed by taking into account longer time steps and the "degree of ecological openness" (Carolan 2006) that extend beyond the "static ex situ" conservation and are found in both "dynamic ex situ" and "in situ" (necessarily dynamic) dispositifs. In contemporary banking practices for forest entities, it is a question of maintaining a system of relationships (a totality) and not just fragments. It is a question of taking into account both human intervention and ecological phenomena; of integrating the idea that we have not only to deal with "living beings" but also with beings capable of "world making" (Tsing 2015): living beings build worlds, and in doing so they adapt to them (which is fundamental in times of global change). In short, banking in forestry consists in preserving individuals, species, "worlds" (produced by interactions) or ecosystems related to the evolution of the biosphere, and this at various timescales. Thus, different science-based conservation systems are at work and aim to enable different activities and, in so doing, emphasize different aspects of forestry banking, all as part of an agency policy.

The objective of this article is to document the banking practices of tree living organisms, or, in other words, forest genetic resources. It is a question of better understanding them, putting them in perspective, drawing from them challenges and lessons on the conservation and uses of forests, on the relationships we 


\section{F. Milanovic and F. Lefèvre}

establish with them, with this type of living. So it is a question of clarifying what is at stake in forest conservation and management practices. To cryoconserve, an impassable horizon? For which future(s)? Which actors? In what way is ex situ conservation insufficient with regard to adaptability issues? This type of conservation is less problematic for annual plants because in a few generations (3-4), re-adaptation can be provided, but this cannot be the case with trees where the generational turnover is $20-25$ years. Thus, this is a specific forest feature that requires particular analytical attention.

\section{A collaborative fieldwork in forestry}

The empirical data used in this paper are based on interdisciplinary research (Milanovic 2014) funded by the French Foundation for the Research in Biodiversity (FRB), from 2011 to 2013, involving substantial sociological fieldwork done by F. Milanovic (FM). The empirical study was realized in 2011-2012 in France, grounded in a qualitative methodology (Glaser and Strauss 1967), which consists of situated observations (the equivalent of 21 days), interviews (50 in total) and the collection of documents. The overall aim of the fieldwork was to investigate the relations between genetic resources and biodiversity, or more precisely, to study current practice in genetic resources management now that biodiversity is prominent in international political and scientific agendas (Takacs 1996). This paper draws on the data concerning forestry, and inside that, poplars. Why forestry? Three characteristics of forestry are quite relevant here. The first one deals with the long time scale in forestry, which generates a particular relationship with regard to uncertainties. Forest management plans have to consider and anticipate forest dynamics over decades or even centuries, which is the time horizon of forest ecosystem dynamics, which fits the velocity of climate change (Loarie et al. 2009). Multiple uncertainties arise at this scale: uncertainties about climatic scenarios beyond 2050, and uncertainties about the long-term response of trees and their complex biotic interactions to annual climatic fluctuations. A second relevant feature concerns the diversity of levels of anthropogenic influence on forests, covering a continuous range of forms from the wild ("pristine" forests) to the intensively domesticated (plantation forests or tree-crop mixed systems). These different forms of forest systems often co-exist in the same landscape and develop various forms of interactions. A third important specific feature of forest systems is that, whatever the degree of human intervention, forest systems are dynamic and they continuously evolve: the genetic composition of a given tree species varies in space and also varies from one generation to the next in each place. Tree species harbor more genetic diversity than other organisms (there are different explanations for this fact), even within a forest (Porth and El-Kassaby 2014). Therefore, depending on the forces driving the forest's dynamic processes (regeneration, growth, reproduction, death), evolutionary changes may be more or less important. 
These processes are simultaneously driven by forest management practices and natural ecological drivers (seed and pollen dispersal, biotic interactions, etc.).

And why the poplar tree? In our fieldwork, this tree was chosen as an entity to be documented in view of the extent of the prism of the uses to which it gives rise, "a genetic resource at the interface between natural habitats of community interest and intensive silviculture" as Lefèvre et al. (2001) says about the black poplar. Moreover, the various poplar species can exchange genes and hybridize (Paffetti et al. 2018), they also exchange pathogens (Xhaard et al. 2011): thus, they form a "species complex" (Pernès 1984). Finally the poplar is a global concern related to improvement practices, with a particular status in France. Here is what a senior official, C. Barthod, who participated in the first European policies for the conservation of forest genetic resources since the 1990s (see below) said:

The question of poplar genetic resources was raised exactly as for all species for which there was a genetic improvement program: there were discussions on the genetic basis from which ... [the breeders] worked. Poplar has always had a rather special regime in France, because there was a national poplar commission with a section dealing with poplars and genetic resources and on the other hand at the FAO level there has always been an international commission, the International Poplar Commission [since 1947], in which France was traditionally relatively present.

This fieldwork is based on a collaboration between a sociologist (F. Milanovic, FM) and a geneticist (F. Lefèvre, FL), the latter of whom was involved in the steering committee of this research and is a geneticist developing his research on microevolutionary processes in forest trees and the impacts of management on the adaptive potential of the forest. This research finds applications in the development of forest genetic resources conservation programs at national and European scale. Knowledge on micro-evolutionary processes in response to disturbance and management are also the basis for the development of evolution-oriented forestry practices (Lefèvre et al. 2014).

In the following, we explore the diversity of the configurations in which living entities are conserved, characterized, propagated, with a particular focus on poplar species. Firstly, we describe these activities related to static ex situ dispositifs: the National Centre of Genomic Resources (CNRGV), and the ex situ collection of the National Commission on Forest Genetic Resources (CRGF). Secondly, we focus on a dynamic ex situ dispositif: the breeding program of a group of scientific interest in poplar (GIS peuplier). Thirdly, we address our attention to the CRGF and its in situ Conservation Units. Dynamic ex situ and in situ organizations are both qualified as "dynamic" because conserved entities are sexually reproduced with genetic recombination (either in a controlled way or naturally, respectively), which is not the case in static ex situ organizations. But first of all, do these three types of conservation involve biobanks? 
If "biobank" is not a vernacular term in forestry, there does exist a veritable set of forestry-related biobank activities. Banking the forest (Halley 2015; Van Dooren 2017) raises a relevant stake for our analysis, because the question of the relations in the ecosystem where biobanking takes place is central: the combination between the (anthropic and non-anthropic) drivers is at work and is linked to in situ and ex situ dispositifs in term of conservation. Of course, being aware of such a diversity supposes a non reductionist epistemology that avoids seeing only genes in forest entities, ${ }^{6}$ as opposed to diverse: populations in situ, individual trees in outdoor collections, in vitro plant collections, cryopreserved embryos and propagules, seed lots, pollen lots, DNA fragments, etc. Whether they are ex situ or in situ conservation dispositifs, with a more or less porous relationship to the environment, in each case there is a core-set of biobanking activities related to the selection of, conservation (and reproduction), characterization, and distribution of certain components of the collection. The comparison of these organizations are not related to in situ - ex situ debates: what is at stake is not the development of cryogenic technologies in ex situ systems, or the cold and frozen preservation practices which are in progress in different fields of conservation (see Radin and Kowal 2017). What matters are interactions between nonhuman organisms, people, ecosystems, their mode of coordination, and the distribution of agency between the several involved entities.

So, we will review the three forms of banking of forest living organisms (static ex situ, dynamic ex situ and in situ), detailing for each of the activities concerned (conservation, research and innovation) the time steps involved, the relevant entities, the vital processes involved and the distribution of the agency involved. Thus we will be able to clearly identify the practices of agency distribution between humans and non-humans, to appreciate the place of what is rationally conceived and the role of uncertainties in forestry banking.

\section{Static ex situ conservation}

Ex situ conservation "is the sustainable preservation of genetic resources outside the site where they were collected. In forestry, seeds, grafts, cuttings or even tissues for in vitro culture. This preservation is called 'static' if it concerns collections maintained in cold rooms or research centres' nurseries." "The primary purpose of the National Collections is the static conservation of genotypes representing the diversity of a species in a given territory" (Collin et al. 2012, 36). This type of conservation is relevant when in situ conservation is not applicable:

(...) for example for species that do not form locally important populations, species that are scattered such as service-tree or have suffered a sharp demographic decline such as elms attacked by graphiosis, or for species that operate in transient populations over cycles of colonization-extinction such as in riparian areas. In situ conservation is then replaced or supplemented by ex situ conservation in the form of collections, generally clonal, maintained in the field or laboratory, the dynamic 
aspect of conservation being then only governed by the renewal of the content of the collections. (Lefèvre and Collin 2012)

\section{The French national collection of forest genetic resources commission}

There is a first form of static ex situ biobank in France that is mainly for forest genetic resources conservation: the national collection of forest genetic resources commission (CRGF). The French national conservation strategy of forest genetic resources, which is simultaneously part of the National Biodiversity Strategy and of the National Plan for Adaptation to Climate Change, aims to preserve the genetic diversity of key forest tree species in the long-term. ${ }^{7}$ Considering the forestry time horizon in regard to climate change velocity and uncertainties, this strategy relies mainly on dynamic conservation that allow the forest genetic resources to keep-on tracking the changes of their environment, (approaches described in the following sections). However, in some cases, such as severe threat or disappearance on the genetic resources in situ, static ex situ is also used as a complementary approach. This is the case in particular for the Elm tree, which is severely threatened by a fungus transmitted by an insect all over the national territory, and also for the black poplar, naturally living in a specific habitat (riparian forest) that has been destroyed due to other land-uses in a large part of the territory. In those case, CRGF has organized surveys and collection of material, vegetatively propagated and conserved in the national nurseries of the National Forest Service (ONF): for example, the black poplar ex situ national collection consists in 290 clones chosen, among a larger number of randomly collected trees in the wild, in order to represent a large genetic and geographic diversity. This national collection is maintained as coppiced trees in Guémené-Penfao. In the case of Elms, the national collection is partly duplicated in cryobank maintained by a private research laboratory (FCBA).

To support and extend the conservation effort beyond the state nurseries, multiclonal varieties each with a large genetic diversity have been derived from the black poplar collection and are commercialized for non-forestry use only (i.e. landscaping). The material clonally distributed and used is genetically identical to the original trees sampled in the wild and entered in the collection.

\section{The National Plant genomic Resources Center}

The National Plant genomic Resources Center (CNRGV) is the second site of static ex situ biobanks with several goals (conservation, research and innovation). CNRGV is a Service Unit of the French National Institute for Agricultural Research (Department of Biology and Plant Breeding) located in Toulouse (South-West France). As one can read it on their website, "The Toulouse INRA Centre stands at the fourth position of all INRA Centers in terms of workforce. It is a reference Centre for Food Toxicology but also for Sunflower with the 
construction of a laboratory of dedicated square meters. Our Centre maintains its level of excellence with the Technological Platforms." ${ }^{8}$ One of these technological platforms is the French Plant Genomic Resources Center (CNRGV), operational since 2004, active in the development of plant genomics in France, where the Genoplant research program plays an important role. Indeed, CNRGV was set up by decision of the Ministry of Research in 2001 to gather together biological material (plant genomic collections of unique value) under the Genoplant Program. Thus its initial brief was to preserve this material and to ensure its best exploitation, either for scientific or economic purposes. It is not focused on forest genetic resources but does contain a number of them (such as poplar and oak). Since this date, it became not only a site for the conservation of biological material, it is also a technology reference center (equipment, know-how) in the production of genomic resources (fabrication, conservation, utilization). Our main investigations of these activities were made during a stay of a week (five days of observation, nine interviews) at this biobank, with one of us (FM) able to observe the incoming flows of plants, their reception, processing, use and conservation. He conducted interviews with most of the people involved (engineers, researchers, quality assurance manager, technician, computer scientists).

\section{To cryoconserve in CNRGV}

During this stay, work was being done to extend the laboratory's premises. Another part was built to increase the storage capacity of DNA samples in refrigerators to $-80^{\circ} \mathrm{C}$, to store the resources they manufacture as part of collaborative projects, and having many projects, the CNRGV lacks space:

That's why we have a building extension project here, we're going to double the surface area, that's it ... We've obtained the funds, the request for funding has been made at the level of both regional and European funds, and so we have a doubling of surface area that is planned, we've already defined the detailed specifications of the building and here it is the call for projects to find the architect. That's it, we'll have buildings, we'll have to fill them up!. (H. Berges, director of the CNRGV, September 2011)

In less than fifteen years, the growth of the CNRGV has been spectacular. This platform is thus a storage place for 447 genomic libraries, 22.8 millions of clone's plant genomic resources of model and crop plants (maize, oak, rice, potato ...). Everything that is stored is therefore based on resources conserved ex situ, statically. Some of it comes from outside, as part of the Genoplant program, another part is carried out on site. Effectively, in addition to pure conservation, CNRGV also prepares genomic resources. After it has been digested in large fragments (with the aid of enzymes), the DNA extracted from the studied plant is cloned within a Bacterial Artificial Chromosome (BAC). Then, this BAC is integrated into bacteria that are resistant to the bacteriophage and that can be reproduced, cloned, and distributed. 
The resulting BAC library is a "model resource" frequently used in physical genome mapping, DNA fingerprinting, sequencing, identification and isolation of genes. Such resources (genomic DNA, large-insert BAC libraries) are fundamental tools in genomics used by a wide range of scientists.

\section{Genomic resources and innovation in $C N R G V$}

These tools can be used for varietal innovation objectives and more fundamental research. For example, S. Vautrin is a research engineer at the CNRGV: she analyses genomes, produces genomic tools, analyses plant genomes and contributes to the construction and screening of BAC banks for the characterization of genomic regions of agronomic interest. As such, she is involved in several varietal innovation projects. In an interview FM conducted with her in 2011, she detailed one of these projects, on wheat, showing how she is using the CNRGV tools she is helping to develop.

The first step is that it was detected that at the level of the $5 \mathrm{~B}$ chromosome of common wheat, there was a part, of which the size and sequence were not known, but which had a role in disease resistance, what we will call a QTL. This associates a region of the genome with a character of interest. Then, the objective is to identify, isolate this part in the DNA and go sequencing, it means to know the ATGC code. To find this region, we need tools, because the wheat genome is 17 giga bases, that is 17 billion CGAT times. So what we need are tools, and that's where the BAC libraries come in, because they're smaller fragments (...). And then we isolate with these samples the area we are interested in. But to find these fragments in a library of several million samples, you need tools. You already have to create this library, so there are millions of samples of small DNA fragments, and then you have to go and look for those millions of samples that interest you. (Interview with S. Vautrin, Research Engineer, CNRGV, September 2011)

The CNRGV produces ex situ genomic resources that play a key role in varietal innovation. Although this platform conserves and uses mainly cultivated plants, it also hosts some forest genetic resources, including poplar Populus trichocarpa, widely used in varietal innovation for the development of hybrid varieties. On its online site you can buy BAC banks "Black cottonwood BAC library" Library, with application perspectives with macroarrays in hybridization protocols. Thus these resources can be used for qualitative screening experiments (to identify genes of interest, based on information from model plant or related species) and can be used to perform gene expression analysis experiments. The plant DNA clones integrated into the bacterial genomes are resources conceived in an "independant" way: only the genotypes of the target species and/or the target sequences themselves are taken into account, without reference to their ecosystem or other kinds of links. Thus scientists in the biotechnology economy understand genes as a source of information (McAfee 2003): they produce standardized and stable objects easily tradable (Parry 2004; Rajan 2006). 


\section{Research at $C N R G V$}

Finally, in terms of research, the CNRGV regularly participates in genome sequencing through international collaborations. For example, the pedunculated oak, which has very recently been sequenced, and knowledge of the genome of which offers prospects for understanding that can be easily connected to more practical issues, as suggested by the publication resulting from this work carried out as part of an international consortium in which the CNRGV participated (as leader, with the CEA). This work, published in the journal Nature Plants on 18 June 2018 (Plomion et al. 2018), ${ }^{9}$ reveals two aspects of the longevity (several hundred years) of this emblematic species. The first documents the particularly rich and diversified arsenal of resistance genes, which allows trees to cope with their large predators (pathogenic fungi, oomycetes, insects, bacteria and viruses) throughout their lives. The second reveals the presence of somatic mutations that can be passed on to the next generation, a result that raises questions about the importance of such, non-germ line mutations in generating genetic diversity in long-lived species.

As the technical head of the CNRGV pointed out in an interview, such resources make it possible to carry out analyses "from existing genomes, and by comparison we can trace the evolution from ancestral genomes that were common."

\section{Banking in static ex situ dispositif}

The plant BAC libraries, fragmented genomic resources, are stored (necessarily ex situ, being "artificially" inserted into the bacterial genome) in monitored $-80^{\circ} \mathrm{C}$ freezers. The storage procedures supporting the production of genomic resources are indexed to instrumental ends concerning both issues of "varietal improvement" and issues of fundamental knowledge (understanding biological mechanisms). Beyond these purposes, these resources are intended to be sequenced, thus disembodied and stripping away for their environmental context. Genomic resources are isolated entities in the sense that with this disembedding they can much easier been considered as "ontologically independent 'object' than if it were an ecological entity that exists in a dynamic relationship with its broader environment" (Carolan 2006). The source of genetic variation of the plant comes exclusively from humans (identify sequences of interest, proceed by transgenesis or controlled hybridization to confer the selected character). The distribution of capacity of action is deeply asymmetric: agency is distributed on the human side. Of course, gene banks represent the embodiment of this logic, as Carolan says, but we should more precisely speak of a gene bank that is part of a static ex situ dispositif. Because with other biotechnologies (Rossi 2014) and in other sites, the relationship to the environment can be more open, we can then talk about ex situ dynamic conservation. 


\section{Dynamic ex situ conservation}

Depending on the species, multi-generation breeding activities are conducted by structured consortia of research organizations and private companies who jointly create new forest varieties (maritime pine and poplar), or by individual research organizations for a few other species. Besides these intensive and long-term breeding programs, for the majority of planted tree species, the selection of forest stands for commercial seed harvesting is determined by the experimental tests conducted by research organizations. Being multi-generational and under controlled conditions, these dispositifs are qualified as dynamic ex situ.

A national poplar breeding program is implemented by a federative structure (GIS peuplier) which assembles public and private research organizations, national forest services (ONF) and union of private forest owners. The objectives of forest genetic resources nurseries are to conserve, make trees available for varietal innovation and set up experimental research systems. These three objectives are present within the administrative nursery of Guémené-Penfao managed by the Office National des Forêts (ONF) in France (Loire-Atlantique (44)). This nursery has been studied as part of our sociological fieldwork because it acts as a genetic conservatory for poplar (among other things). For this reason, FM spent a day (of observation) there, and conducted two interviews on site, with the director of the nursery and a technician, which are in addition to two other interviews with two researchers who regularly use this nursery for their research activities: M. Villar and C. Bastien.

\section{Conservation}

The type of conservation carried out is described as "dynamic ex situ": it is, as before, a matter of sustainably preserving genetic resources outside the site where they were collected (ex situ), except that, unlike static ex situ conservation, this conservation is called dynamic in the sense that conservatory plantations or seed orchards give rise to new forest populations by sexual reproduction (Collin et al. 2012). The resulting genetic mixing gives the dynamic nature of this conservation. In the context of conservation for heritage reasons, the State covers the related costs and, at the operational level, the nursery organizes collaboration between its own technicians and the researchers in charge of managing this conservation, as indicated here by the director of the nursery:

If it is for the conservation of genetic resources, it is in the missions of the State. So it is the State that pays for everything. You, the research institutes, are given the task of ensuring the scientific management of conservation, you will work in collaboration with Guémené who will ensure the technical operations. (interview with $\mathrm{H}$. Le Bouler, director of the Guémené-Penfao nursery, July 2011)

Ex situ conservation is highly reductionist (Bonneuil, Foyer, and Wynne 2014; Carolan 2006; Fullilove 2017; Van Dooren 2010), but the degree of ecological 
openness can vary, as one can see it in the dynamic ex situ conservation dispositif that is the Guéméné nursery. As Carolan explained in his study of a Heritage Seed Bank (Carolan 2007), the Guéméné nursery develops a type of ex situ conservation which is a more "open" form than that found at the CNRGV. Here with the case of trees, this degree of ecological openness generates an agency variation (between closed and semi-closed), in both breeding programs and research projects.

\section{Research in nurseries}

Keeping trees in nurseries can also be used to study their genetic diversity. Black poplars are found in the nursery of Guéméné. Marc Villar is a population biologist, specialist in black poplars. ${ }^{10} \mathrm{FM}$ conducted a long interview with him and accompanied him several times, including to the Guéméné nursery. The genetic diversity of trees can be studied in experimental nursery apparatus, where it is the evolution of ex situ adaptive traits that can be explored. As part of the French program for the conservation of black poplar genetic resources, five experimental systems relating to black poplar have been installed by Mr. Villar at the Guémené-Penfao forest nursery since 2004.

Why do we do things in the nursery? An individual, a phenotype, is the conjunction between his parents' genes and the environment; if I do flowering phenology, there will be both genetic diversity due to the genes of these individuals and the environment. Between the Rhin, the Loire and the Garonne, the environment is very different, so I couldn't say if it's due to the environment, or due to genetics. We collect plant material, cuttings, make copies of it, and put all this plant material on a single environment. Here we have very, very classic systems: the environment is unique, so there we see what we want to see and we are sure that what we see is the genetic part and not the environment. Classic, we didn't invent anything, everyone does that. That's why we're doing these experimental systems: here I'm comparing trees from Corsica, the Loire de Belle-Ile-en-Mer, etc., in a single environment. (interview with M. Villar, March 2011)

At the time of our research (2011), experiments were in progress at the nursery, and data were being analyzed. These were studies of classical traits of phenotypic variability in black poplar: foliar phenology, leaf area, growth, branch angle, branch angle (Villar 2011). ${ }^{11}$ In research projects using Guémené-Penfao nursery, individual genes are not the direct objects of research as it is the case in CNRGV. Here, the object of interest is the young tree, the clone (group of trees that share the same genotype), the progeny (group of trees that share the same parents) or the population (group of trees that share the same geographical origin). These objects are compared regarding their relative "genetic performance," which is inferred from the comparison of their "phenotype" in a common environment. Thus, the environment is homogenized among research objects to allow inference not just on a single gene, nor a finite number of genes, but on the global genome with all genes acting and interacting together in the controlled environment. 
While such studies can contribute to the search for a possible geographical structuring of genetic diversity, and thus guide the choice of conservation sites for black poplar, they can also be part of varietal innovation objectives.

\section{Breeding in nurseries}

The Guéméné nursery is also a site involved in the creation of poplar varieties, but not under the same conditions as before, since the breeders using the nursery must pay custody fees: "Because it costs to collect, keep alive and identify" (interview with Le Bouler). Concerning poplars, populiculture raises important industrial and economic issues. ${ }^{12}$ Developing poplar varieties resistant to pest populations is a real challenge. Leaf rust is one of those pathogens that have decimated poplar plantations. This has led to a shift in varietal innovation practices (at the begining of the 2000s), with a focus on indigenous species in crossbreeding: the challenge is to take into account the "geographical embeddedness," meaning the extent to which local context is valorized in the breeding program (Stone and Glover 2016). Catherine Bastien, a geneticist specializing in varietal innovation with poplar, ${ }^{13}$ was confronted with this problem: following the ravages caused by leaf rust, she now uses black poplars in varietal innovation:

Certainly [in the natural environment] we see individual damage, but it never puts a population at risk. So let us look at what is happening in these riparian areas so that, finally, the process we do in extraction, in fact in the selection of the genetic resource, we use it. We have returned to formulas where we say "well, it is fininished to work only with exotic material that has not co-evolved with pest populations, possibly even with soil mycorrhizal populations, we will refocus the valuation on at least one related species that is indigenous, local, the black poplar that has regained importance in breeding programs. So the black poplar alone does not meet the needs of populiculture, but it hybridizes with one of these North American species, the cottonwood, and that is the answer. So we have seen a reorientation over the past 15 years (...) with the idea of saying "let us value everything that is plasticity, adaptations to environmental conditions, adaptation to the parasitic procession, of what is in black poplar." (interview with C. Bastien, April 2012)

If black poplar offers a genetic diversity that can be mobilized in innovation practices, ${ }^{14}$ there follows a selection phase in which the nursery plays an essential role:

Because basically, every year, I create about 25 crossing families, 150 individuals per family. This is a basic material. And we, every 5 years, start to do steps to purge this equipment, that is to say, we make selections in stages. In the first selection phases, we make selections in the nursery, on the basis of global adaptation, it must look like a tree, it must be a resistant wood ... Finally, we really make a selection in the nursery, under natural conditions. (interview with C. Bastien, April 2012)

Indeed, in the new selection schemes to which C. Bastien contributes, ${ }^{15}$ based on the genetic diversity of natural populations is an important point. This geographical embedding is a redistribution of agency between humans and non-humans since it 
is in the wild that trees with the best capacity for resistance to pathogens will be found and integrated in the process of innovation.

\section{Banking in dynamic ex situ dispositif}

In their study of Golden Rice, Stone and Glover (2016) argue that "global industrial agriculture has been built on a 'systemic placelessness' typified by crop breeding based on an underlying modernist philosophy that nullifies place." This philosophy was also underlying the poplar breeding programs until it encountered difficulties related to pathogens. Nowadays, a part of the capacity for action of improved varieties is sought within local species. Unlike in the static ex situ conservation, where it is displaced, here the environment is present, although differently depending on the activities involved. It is "controlled" for scientific purposes (study of phenotypic plasticity) or, during industrial challenges in varietal innovation, is considered as a source of local adaptation and resilience. It is another way of distributing the agency between human and non-human entities that is at stake, where unintentionality occupies a greater place. Indeed, it is not humans who are responsible for the phenotypic variations observed in the trees studied and who will nevertheless be useful to them in their own activities.

\section{In situ conservation}

The French national forest genetic resources conservation program is supervised by CRGF, where forest administration, research institutes, public and private forest owners, nature protection agencies and NGOs are involved. As part of the sociological survey, FM conducted two interviews with people involved in this policy: C. Barthod (engineer, Ministry of Ecology), involved since 1990 in the emerging policy of FGR, and Eric Collin (IRSTEA), secretary of the CRGF, to which must be added the interview with M. Villar (head of the conservation unit for black poplar in the CRGF). FM also went to the one day symposium on the 20th anniversary of this policy organized by the CRGF (chaired by FL since 2006), with a special issue in the RDVT Journal. In addition, as President of the CRGF, FL is the French representative in the Steering Committee of the European Forest genetic Resources Program (EUFORGEN).

The FGR conservation infrastructure includes both a network of dynamic in situ conservation units - currently 96 forests specifically dedicated to forest genetic resources conservation of nine target species across the territory - and ex situ collections of eight species in seed banks, clonal archives in the field, or cryobanks (Lefèvre and Collin 2012). There is also a pan-European coordination of national FGR conservation activities through the EUFORGEN program. These conservation Units can be considered as a way of banking forest since they are conserved (and protected against fires, game damages and so on), characterized and some of its individuals are "distributed," as we will see. 
To conserve in situ

Noting that forest genetic resources and their natural dynamics are impacted by various types of human activities (e.g. forest management, landscaping, transport infrastructures, etc.), French national policy for the conservation of forest genetic resources, initiated in 1990, has been oriented primarily towards raising awareness among the stakeholders concerned. It is indeed necessary to go back to the First Ministerial Conference for the Protection of Forests in Europe, held in Strasbourg in 1990, to find the premises of a European policy on forest genetic resources, to be implemented within each State involved. It was on this occasion that a national policy for the conservation of these resources was formalized, of which the CRGF is an offshoot (in 1992). As this engineer, who was present from the very beginning of this policy in Strasbourg, said:

It was born much more generally from all the questions about strategies for improving genetic resources and the genetic basis to be conserved for species for which improved varieties were expected. (interview with C. Barthod, Ministry of Ecology, Sustainable Development, Transport and Housing; Sustainable Development - General Council for Environment and Sustainable Development, December 2011)

The Commission considers that most of the genetic resources can only be conserved through current silvicultural management practices, forest and land management as well as in public policies. ${ }^{16}$ Then, she acts to set up a specific conservation network throughout the metropolitan area for a few forest species chosen on the basis of their economic or ecological interest and the threats to their genetic diversity. Finally, the Commission "takes into account the two dimensions (heritage and evolutionary ${ }^{17}$ ) of forest genetic resources in protected areas and networks for the conservation of existing habitats," which is not without difficulties because it involves changing existing management approaches so that they integrate forest genetic resources and these two dimensions. We are therefore dealing with the management of a heritage which, in order to preserve its evolutionary dimension, proceeds from a management of the processes inherent to it. Preserving an adaptive process is the fundamental challenge. For details, see the RDVT review and its special issue on the Commission's twenty years of existence $\left(\mathrm{N}^{\circ} 36-37,2012\right)$.

\section{In situ research}

In situ, genetic diversity is also the subject of assessment of adaptive traits, with the idea that it is by relying on the criterion of the evolution of this diversity that human actions, including those dedicated to the management of natural areas with a protection purpose, can be guided and evaluated. It is precisely in this spirit that the CRGF works. The information that can be extracted from these observations is intended to guide the selection of future in situ black poplar conservation sites 
(as part of the CRGF conservation networks where Marc Villar is responsible for the black poplar network).

If the phenological study is of interest in terms of knowledge of the mechanisms involved, it is therefore also linked to "ecological engineering" actions in the sense of stewardship of natural processes in the form of management of Conservation Units (with the CRGF, see above), where biodiversity is central, both in terms of the perpetuation of the species itself and its interest for humans facing upheavals linked to climate change. The development of a scale for scoring phenological stages by M. Villar and M. Chantereau, curator of the St-Mesmin National Natural Reserve (on the Loire in the Loiret), illustrates this example. "I deliberately built this 5 -stage scale (...) with this naturalist, so that it would be accessible to managers accustomed to field observations but not accustomed to intraspecific diversity observations" (Villar 2011, 30). This scale was used as part of a floral phenology study conducted on 14 populations of the Loire River ("Poploire") financed by the Regional Department of the Environment, Development and Housing from 2006 to 2009. These data, compiled using this scale, were being analysed in 2011 and were destined to be scientifically validated (Villar 2011; Villar et al. 2016). At the same time, another form of valuation of the scale was implemented by its protagonist by equipping the choices of the future Black Poplar Conservation Units of the CRGF.

Another type of research in the in situ conservation dispositif is to use genetic markers, not for themselves, but for the information on past or on-going ecological and evolutionary processes that can be revealed from the structure of their diversity: past demography, pollen and seed dispersal, selection. So, "what distinguishes this technology from direct sequencing is how it requires population geneticists to consider genetic data in parallel with extra-genetic characteristics of organisms and environments" (Rossi 2014, 70). Here, the objective of the research is not to characterize a particular state of the forest genetic resources (individual genes as in CNRGV, or whole genotypes as in the nursery), the objective is to understand the ecological and evolutionary processes that continuously reshape the forest genetic resources in the ecosystem.

In situ innovation: renewing diversity

In situ, sexual reproduction among the adult trees occurs naturally, i.e. new families are created each year that are not chosen by humans as in the previous case. Furthermore, natural selection proceeds all along the life cycle of the trees, eliminating the less fit individuals. In trees, the intensity of selection is higher in the juvenile stage when there is a drastic reduction of population size. Survival probability and reproductive success determine the fitness of each tree, i.e. the number of progenies left to the next generation. The fitness is not equal among individuals and this leads to Darwinian selection and genetic evolution of the population. In situ, the processes that drive the evolution of the genetic resources (random genetic 
drift, selection, mating and gene flow), are more "natural" than controlled. This allows the drivers of evolution to evolve themselves: there is a co-dynamic between the genetic evolution of the population and the changes of the drivers of this evolution. In that sense, in situ innovation is able to follow the changes in the environmental demand. Actually, the drivers of genetic evolution can be indirectly impacted by human activities, whether this be desired or not: this is used in the in situ conservation units of CRGF where management is strictly limited just to ensure that evolutionary processes are effective (i.e. keep sufficient adult trees, without choosing them, to ensure sexual reproduction to occur, or protect against over-grazing by game to allow the new generation to emerge)

In addition to this "natural" innovation within the in situ conservation units, particular genetic resources can also be identified there and selected to feed the dynamic ex situ program previously described. We have seen earlier that C. Bastien used new forest tree selection tools that take into account "the history of individuals in the populations from which they come and therefore in the dynamics of diversity as it has been done by the evolution of these natural populations" (interview). These natural populations are of course in situ. And it is sometimes on the occasion of their field trips (dedicated to harvesting) that M. Villar and his colleague technician from the Guéméné nursery, O. Forestier, ${ }^{18}$ identify individuals and bring them back to the nursery where $\mathrm{C}$. Bastien may consider the interest of integrating them into a varietal innovation scheme. As tells it O. Forestier:

Sometimes with Marc when we're out harvesting, Marc says to me "Oh yes I'll take that tree there" and then I say "here I'll take that one." He says to me "oh not so good!," and I say to him: "Yes! it is very good for Catherine," Catherine Bastien. And when I tell him "it is good for Catherine," implied "it has a log, it has a very straight trunk, it has a port that is beautiful, it is healthy" and therefore implied that it can make an interesting genitor for future crosses. (interview with O. Forestier, July 2011)

\section{In situ banking}

The choice of in situ conservation units mobilizes research since it is necessary to select areas and this choice must be justified in view of the intraspecific diversity present in this area. This intraspecific diversity is by no means a human artifact. Admittedly, it is not a question of actualizing a dualism in which nature and humans are perceived as ontologically distinct. It is rather a question of co-evolution, but without intentionality. Similarly, in breeding programs, broodstock to be found in the wild do not owe anything to varietal innovation activities, although they are likely to contribute to them. As we can see, it is in situ that the agency distribution gives a lesser role to humans and a greater role to non-human, biotic or abiotic organisms. The consequences of an in situ conserved nature, of ecosystems conserved over the long term, is that the distribution of the agency between these no 
humans entities and humans, what Tsing designed as "polyphonic assemblages" (Tsing 2015) must be coordinated. ${ }^{19}$

\section{Conclusion}

At the beginning of this paper we pointed out that conservation practices tend to be taken for granted in terms of their justification, but the richness of their diversity is seldom recognized. When studied more closely, it appears that the conservation systems of forest entities contain a consistent heterogeneity. It is first of all found in the diversity of types of entities in the biobanking system, from DNA samples to dynamic populations. The heterogeneity also lies in the vital processes regulated: generation, maturation (including characterization), reproduction, selection, destruction. It is also found in the diversity of the time scales involved, from short-term (the current entity) to long-term (all its potential descent). Finally, it is located in the forms of interaction with the environment (static ex situ (cryobank), nursery, experimental situation, in situ).

Among these practices, the modalities of coordination between humans and nonhumans are contrasting. Indeed, humans may not be the only actor driving the vital cycle of the entities in the biobanking system: three modes of agency may be attributed to the different entities themselves depending on how their vital processes come into play in biobanking practices.

In the first mode, no agency at all is recognized in the sense that all the organism's biological processes are neglected or supposed to be under full control; here the entity is actually considered to be a "mineral resource," and seen as a "necro-entity." This is the case, for example, of a DNA fragment stored in a buffer or in a BAC, this is also the case with static ex situ conservation.

In the second mode, agency is recognized only before its entry into the biobank (up to the identification step), but not once it has entered the biobank during collection, characterization, conservation, distribution and reshaping activities. Here the genetic resource is recognized to have been shaped through its own evolutionary processes, e.g. local adaptation processes, before entering the biobank system, but, once there, all vital processes are fully controlled to satisfy well-identified target objectives. Here dynamic ex situ conservation with breeding programs are concerned.

In the third mode, agency is considered itself as a characteristic of interest that contributes to innovation within the biobank: this is the case with dynamic in situ conservation where natural reproduction and natural selection processes occur spontaneously. Here, biobanking system is more about guidance than total control. The idea is to manage the processes by letting them operate, rather than controlling everything. In the context of change and uncertainty, when unpredictable events are expected, this mode of agency takes benefit of the entity's property of evolvability to contribute to innovation and therefore, potentially increase the future capacity of response to unforeseen demands while maintaining current 
adaptation. This mode of agency receives increased interest in the current forest banking practices.

Depending on the situation, the arrangement that is thus conferred on biotic entities results from a variable geometry arrangement of these components. The combinations are multiple because of the malleability of natural entities capable of a plurality of modes of existence (in their relationships with humans and in the environment). Recognition of the plurality of modes of existence is just a starting point. It is then a challenge for an agency policy to establish and stabilize such modalities, to adjust the settings between them, in short, to make various uses of nature compatible. If governing life means "intervening on its paths, limiting its trade, framing its transformations, controlling its living and reproductive conditions" (Lascoumes 1994, 317), then the redistribution of properties between humans and non-humans, the redefinition of the components of their agency, the differentiation of their relations with the environment, all this raises with force the issues of governing life. Our argument is that "political work" (Dodier 2003) is at stake, which consists in assigning powers to entities, in distributing capacities for action between various biotic entities (including humans) and their environment. Studying this work aims to shed light on the issues of governance of living organisms that are experienced in the banking of living organisms, and more particularly in forestry.

On this point, we have seen that the first mode of agency (in static ex situ conservation) confers an agency on humans that is disproportionate to that accorded to non-humans. In dynamic in situ conservation, however, the arrangement is less asymmetrically distributed between humans and non-humans. From one to the other is at stake the degree of transformation, manipulation, anthropization, in short, the formatting of non-human biotic entities in order to mobilize them in a human action course.

Political work with regard to life is confronted with the art of reconciling ecological and human dynamics, or, in other words, the art of articulating nature and society by ensuring that an arrangement is assigned to nature that integrates its dynamic properties of resilience and operational autonomy. More precisely, the reproducibility of the biotic entities to be maintained and their adaptability to be preserved designate the space of what a dynamics of regulation of living organisms must cover.

Having less control over living organisms is a topical issue in current practices for banking forest living organisms. More generally, the desire for control that presides over the logic of ex situ conservation echoes a logic of in situ conservation that leaves much more autonomy to the living, with the challenge of allowing unexpected combinations of genes to occur, to allow the advent of new species or varieties (by hybridization), to increase the adaptability of the living in in situ spaces. It is a question of conceiving differently the agency distribution and its consequences. There is here a kind of "policy of agency" in the sense that is at work another way to coordinate human intervention and ecological phenomena; of declining in terms of 
action the idea that we have not only to deal with "living beings" but also with beings capable of "world making" (Tsing 2015). This is the second side of this policy (the first one dealing with control): taking into account that living beings build worlds and these one (partially) escape to our scope of action. And to allow or encourage their emergence is a horizon of actions.

\section{Acknowledgements}

This research was supported by the French "Fondation pour la recherche sur la biodiversité." We thank our colleagues from the steering committee who provided insight and expertise that greatly assisted the research, although they may not agree with all of the interpretations of this paper. We would also like to show our gratitude to the interviewed persons for sharing their time with us during the course of this research, and we thank two "anonymous" reviewers for their so-called insights.

\section{Disclosure statement}

No potential conflict of interest was reported by the author.

\section{Funding}

This research was supported by the French "Fondation pour la recherche sur la biodiversite,", as part of a post-doctoral research project conducted at the École Normale Supérieure de Lyon, from 2011 to 2013, in Lyon (France).

\section{Notes}

1. Here we use the term forest genetic resources in its common sense (FAO 2014), which specifically refers to the trees and not to the other organisms that compose the forest ecosystem.

2. R. Harrison qualified the conception of the relationship between diversity and time as underlined by an "entropic view", "one in which diversity naturally tends to decrease with time and in which time itself is perceived to represent an implicit threat to biological and cultural diversity" (Harrison 2017). According to Harisson, this perspective has led to the 2004 International Treaty on Plant Genetic Resources for Food and Agriculture and is conferring legitimacy to the creation of a global ex situ system for the cryoconservation of agricultural plant genetic resource diversity. "The freezing of seeds would enable the maintenance of agrobiodiversity (...), resulting in an 'archive' of the evolutionary histories of crop varieties that might be of use to future generations of agricultural scientists and farmers." (Harrison 2017). In his article, Harrison develops a criticism of these conservations practices (can we really talk about an "archive"? Is it certain that these "archives" will be adapted to the future?), arguing that the "taken for granted" nature of the merits of conservation, following entropic view, has prevented further reflection on the various types of conservation.

3. In his second conference on the new climate regime, Latour (2017) develops the idea that only what is inert has no power to act. But Gaia, and as far as we are concerned here, forests, are not inert. They are therefore equipped with capacities for action that must be analyzed in their relations with humans. The concept of agency is a way of challenging the distinction between humans and non-humans. It is in this sense that we use it here.

4. In science studies, A. Pickering published in 1995 a pioneer study using the concept of "agency". The key move of his book "The Mangle of Practice" was to focus on performance rather than cognition. He wanted to understand scientific practice without separating on one side what 
scientists do; on the other side the performance of the material world. He wanted to understand the "performative struggles between the two". One concept he used was "agency" to refer directly to action, doing things that are consequential in the world. The key idea of The Mangle was that scientific practice has the character of a "dance of agency" between people and things, the human and the nonhuman (Pickering 1995, see also (Pickering 2013)).

5. The Foucauldian concept of "dispositif" is difficult to translate from French into English. However, it tends to be used as it is in English: when we search for this term in the Web of Science, we find 464 references that use it in English (research done in november 2018). We therefore use it as it stands in this text to refer to "everything that has, in one way or another, the ability to capture, orient, determine, intercept, model, control and ensure the gestures, conduct, opinions and speech of living beings." (Agamben 2007, 31)

6. See Carolan's work on seeds (Carolan 2007).

7. http://agriculture.gouv.fr/la-politique-nationale-de-conservation-des-ressources-genetiquesforestieres, visited on 10 January 2018.

8. http://www.toulouse.inra.fr/en/Center-Research/Inra-Occitanie-Toulouse-Research-Center/ Key-figures, visited on 10 January 2018.

9. The Director of the CNRGV, H. Berges, is co-author of this article.

10. He is director of Research at INRA and also in charge of the Black Poplar Conservation program at the Forest Genetic Resources Commission. He is now director of the research unit BioForA in Orleans.

11. Let us take an example of an experimental system implanted in the experimental nursery and described in one of the publications that followed it: "Seeds of black poplar and white willow, derived from mature inflorescences of the species P. nigra and S. alba of the SaintMesmin National Natural Reserve, are sown under controlled substrate conditions. Two substrates are tested, sandy and sandy-gravelly (...). For each species, the seeds are sown on unit trays of about $1 \mathrm{~m}^{2}$ with a density of 345 seeds per $\mathrm{m}^{2}$ and direct exposure to sunlight. (...) From this system, three experiments are tested: (i) a control experiment: identification of the influence of the germination substrate on growth and root structure; (ii) a pull-out experiment: measurement of the forces required to pull seedlings; (iii) a burial experiment: determination of the survival capacity of the seedlings at the sand deposit." (Lise et al. 2017).

12. The surface area of populiculture (187,000 ha) represents $1 \%$ of the French forest, and the resulting wood production amounts to 2.6 million $\mathrm{m}^{3}$ per year ( $3 \%$ of total wood production).

13. Specialized in the study of the structure and evolution of the genetic diversity of poplar and Scots pine under the influence of natural (biotic and abiotic constraints) or artificial (improvement programs) selection, C. Bastien is an agronomist, geneticist, research director in the research division "Forest, Grassland and Freshwater Ecology" at INRA, which she has headed since 2018. In 2011, she was involved in this division in the "Forest Improvement, Genetics and Physiology" Unit, in Orléans.

14. It should be recalled that the "base material » used to initiate the breeding programs consists of individuals selected for their desired characteristics (tree shape, disease resistance, and other quality, adaptation and resilience traits) within the static ex situ collection and/or in the wild. These entities are used to make controlled crosses. The characterization of parents and progenies is performed in controlled conditions for (1) the release of new varieties and (2) the design of the next generation cycle.

15. At the time of the survey she was coordinating the European Noveltree project (2008-2012)- the complete tittle is "Novel tree breeding strategies" - whose ambition is to develop new tools for selecting forest trees. One can find the Final Report Summary - Noveltree here: https://cordis. europa.eu/result/rcn/57830_en.html

16. In 1999, the Charter for the Conservation of Forest Tree Genetic Resources drafted by the CRGF was signed by 25 organizations. 


\section{F. Milanovic and F. Lefèvre}

17. "Forest genetic resources management has two dimensions, a heritage dimension to conserve and exploit existing adaptations, and an evolutionary dimension to facilitate the generation and propagation of new adaptations" (Lefèvre and Collin 2012, 11).

18. Since our investigation, O. Forestier has become the director of the Guéméné-Penfao nursery.

19. That is the role of the CRGF in France: in the management charter for in situ units, a commitment is made to promote regeneration (e.g. by protecting against fire or game damage); and the role of Euforgen in Europe.

\section{References}

Agamben, G. 2007. Qu'est-ce qu'un dispositif? Paris: Payot.

Bidet, A., M. Boutet, and F. Chave. 2013. "Au-delà de l'intelligibilité mutuelle: l'activité collective comme transaction. Un apport du pragmatisme illustré par trois cas.” Activités 10 (1): 172-191.

Bonneuil, C., J. Foyer, and B. Wynne. 2014. "Genetic Fallout in Bio-Cultural Landscapes: Molecular Imperialism and the Cultural Politics of (not) Seeing Transgenes in Mexico." Social Studies of Science 44 (6): 901-929.

Carolan, M. S. 2006. "Conserving Nature, but to What End?: Conservation Policies and the Unanticipated Ecologies They Support." Organization \& Environment 19 (2): 153-170.

Carolan, M. S. 2007. "Saving Seeds, Saving Culture: a Case Study of a Heritage Seed Bank." Society \& Natural Resources 20 (8): 739-750.

Collin, E., H. Le Bouler, O. Forestier, J. P. Huvelin, M. Rondouin, P. Brahic, M. Bariteau, et al. 2012. "Conservation ex situ : Collections statiques et valorisation dynamique." Rendez-Vous Techniques ONF 36-37: 36-39.

Conein, B., N. Dodier, and L. Thévenot. (dir.). 1993. "Les objets dans l'action. De la maison au laboratoire." Raisons pratiques. Paris: EHESS.

Dodier, N. 2003. Leçons politiques de l'épidémie de sida. Paris: Ed. de l'E.H.E.S.S.

FAO. 2014. "Global Plan of Action for the Conservation, Sustainable Use and Development of Forest Genetic Resource." Commission on Genetic Resources for Food and Agriculture, FAO, Rome, 31p.

Fenzi, M., and C. Bonneuil. 2016. "From "Genetic Resources" to "Ecosystems Services": A Century of Science and Global Policies for Crop Diversity Conservation." Culture, Agriculture, Food and Environment 38 (2): 72-83.

Fullilove, C. 2017. The Profit of the Earth. Chicago: The Chicago University Press.

Glaser, B., and A. Strauss. 1967. The Discovery of Grounded Theory: Strategies for Qualitative Research. Chicago: Aldine Publishing Company.

Halley, M. 2015. "Case Study on New Forests' Malua Biobank Initiative.” In Background Paper for State of the Apes: Industrial, Agriculture and Ape Conservation, 1-7. Cambridge: Cambridge University Press.

Harrison, R. 2017. "Freezing Seeds and Making Futures: Endangerment, Hope, Security, and Time in Agrobiodiversity Conservation Practices." Culture, Agriculture, Food and Environment 39 (2): $80-89$.

Holling, C. 1973. "Resilience and Stability of Ecological Systems." Annual Review of Ecology and Systematics 4: 1-23.

Lascoumes, P. 1994. L'éco-pouvoir. Environnement et politique. Paris : La Découverte.

Latour, B. 1994. "Une sociologie sans objet? Note théorique sur l'interobjectivité." Sociologie du travail 36 (4): 587-607.

Latour, B. 2017. Facing Gaïa. Cambridge: Polity Press.

Lefèvre, F., N. Barsoum, B. Heinze, D. Kajba, P. Rotach, S. M. G. de Vries, and J. Turok. 2001. EUFORGEN Technical Bulletin: In Situ Conservation of Populus nigra. Rome, Italy: International Plant Genetic Resources Institute. 
Lefèvre, François, Thomas Boivin, Aurore Bontemps, François Courbet, Hendrik Davi, Marion Durand-Gillmann, Bruno Fady, et al. 2014. "Considering Evolutionary Processes in Adaptive Forestry." Annals of Forest Science 71: 723-739.

Lefèvre, F., and E. Collin. 2012. "Conserver les RGF en France et en Europe: objectifs et méthodes." Rendez-Vous Techniques ONF 36-37: 10-13.

Lise, Wintenberger Coraline, Stéphane Rodrigues, Philippe Jugé, and Marc Villar 2017. "Survie des Semis de Ligneux Pionniers Dans les Lits Fluviaux: Approche in et ex Situ des Facteurs de Contrôle Abiotiques et Biologiques des Espèces Populus Nigra et Salix Alba." Géomorphologie : Relief, Processus, Environnement 23 (3): 233-252.

Loarie, S., P. Duffy, H. Hamilton, G. Asner, C. Field, and D. Ackerly. 2009. "The Velocity of Climate Change." Nature 462: 1052-1055.

McAfee, K. 2003. "Neoliberalism on the Molecular Scale: Economic and Genetic Reductionism in Biotechnology Battles." Geoforum; Journal of Physical, Human, and Regional Geosciences 34: 203-219.

Milanovic, F. 2014. "De la diversité des modes d'existence du vivant. Une approche sociologique." Research funded by Fondation pour la Recherche sur la Biodiversité, Rapport. http://www. fondationbiodiversite.fr/images/stories/telechargement/MODELO/Impression_interieur_RG_ Et_Societe_web.pdf.

Paffetti, Donatella, Davide Travaglini, Mariaceleste Labriola, Anna Buonamici, Francesca Bottalico, Alessandro Materassi, Gianni Fasano, Susanna Nocentini, and Cristina Vettori. 2018. "Land Use and Wind Direction Drive Hybridization between Cultivated Poplar and Native Species in a Mediterranean Floodplain Environment." Science of the Total Environment 610-611: 14001412 .

Parry, B. 2004. Trading the Genome. New York: Columbia Press.

Pernès, J. 1984. Gestion des ressources génétiques des plantes. Paris: Lavoisier.

Pickering, A. 1995. The Mangle of Practice. Time, Agency and Science. Chicago: University of Chicago Press.

Pickering, A. 2013. "Being in an Environment: A Performative Perspective." Natures Sciences Sociétés 21 (1): 77-83.

Plomion, Christophe, Jean-Marc Aury, Joëlle Amselem, Thibault Leroy, Florent Murat, Sébastien Duplessis, Sébastien Faye, et al. 2018. "Oak Genome Reveals Facets of Long Lifespan." Nature Plants 4: 440-452.

Porth, I., and Y. El-Kassaby. 2014. "Assessment of the Genetic Diversity in Forest Tree Populations Using Molecular Markers." Diversity 6: 283-295.

Radin, J., and E. Kowal, eds. 2017. Cryopolitics. Frozen Life in a Melting World. Cambridge: MIT Press.

Rajan, K. 2006. Biocapital: The Constitution of Post-Genomic Life. Durham: Duke University Press.

Rossi, J. 2014. "Genes are not Information: Rendering Plant Genetic Resources Untradeable Through Genetic Restoration Practices." Geoforum; Journal of Physical, Human, and Regional Geosciences 55: 66-75.

Soulé, M. E., and B. A. Wilcox. 1980. Conservation Biology. An Evolutionary-Ecological Perspective. Sunderland: Sinauer Associates Inc.

Stone, G. D., and D. Glover. 2016. "Disembedding Grain: Golden Rice, the Green Revolution, and Heirloom Seeds in the Philippines." Agriculture and Human Values 34 (1): 87-102.

Takacs, D. 1996. The Idea of Biodiversity: Philosophies of Paradise. Baltimore: Johns Hopkins University Press.

Thévenot, L. 1994. "Le régime de familiarité. Des choses en personne." Genèses 17: 72-101.

Thévenot, L. 2011. ““'On Engagement, Critique, Commonality, and Power,” an Interview by Paul Blokker and Andrea Brighenti." European Journal of Social Theory 14 (3): 383-400.

Tsing, A. 2015. The Mushroom at the End of the World. On the Possibility of Life in Capitalist Ruins. Princeton: Princeton University Press. 
Van Dooren, T. 2010. "Banking Seed: Use and Value in the Conservation of Agricultural Diversity." Science as Culture 18 (4): 373-395.

Van Dooren, T. 2017. "Banking the Forest: Loss, Hope, and Care in Hawailan Conservation." In Cryopolitics. Frozen Life in a Melting World, edited by Joanna Radin, and Emma Kowal, 259-282. Cambridge: MIT Press.

Villar, M. 2011. Conservation des ressources génétiques du peuplier noir dans son habitat : bases biologiques, génétiques et écologiques. Orléans (France): HDR. Université d'Orléans.

Villar, Marc, Sylvie Augustin, Michel Chantereau, Richard Chevalier, Olivier Denux, Sabine Greulich, Vanina Guérin, et al. 2016. "Consequences of fluvial maintenance operations on the sediment morphodynamic and the associated biodiversity in the mosaic of Mareau-aux-prés islands." [Oral Presentation]. International Long-Term Ecological Research Network ILTER 1ST Open Science Meeting (2016-10-10-2016-10-13) Skukuza Kruger National Park (ZAF).

Von Detten, R. 2011. "Sustainability as a Guideline for Strategic Planning? The Problem of LongTerm Forest Management in the Face of Uncertainty." European Journal of Forest Research 130: 451-465.

Xhaard C., Fabre B., Andrieux A., Gladieux P., Barrès B., Frey P., Halkett F. 2011. "The Genetic Structure of the Plant Pathogenic Fungus Melampsora Larici-Populina on its Wild Host is Extensively Impacted by Host Domestication.” Molecular Ecology 20 (13): 2739-2755. 